\title{
Projection Pursuit Regression on Statistical Downscaling Using Artificial Neural Network and Support Vector Regression for Rainfall Forecasting in Jember
}

\author{
Chandrika Desyana Putri ${ }^{1}$, Ema Fahma Farikha ${ }^{1}$, Alfian Futuhul Hadi ${ }^{1, *}$, \\ Yuliani Setia Dewi ${ }^{1}$, I Made Tirta ${ }^{1}$, Firdaus Ubaidillah ${ }^{2}$, Dian Anggraeni ${ }^{1}$
}

\author{
${ }^{1}$ Data Science Research Group, Department of Mathematics, University of Jember, Jember 68121, Indonesia \\ ${ }^{2}$ Department of Mathematics, University of Jember, Jember 68121, Indonesia \\ *Corresponding author. Email: afhadi@unej.ac.id
}

\begin{abstract}
Information about rainfall is very necessary for the country of Indonesia which bears the title of an agricultural country. This is because the agricultural sector is very vulnerable to climate change, where rainfall is one indicator of climate change-related to crops. Therefore, an accurate rainfall forecasting model is needed to assist farmers in determining planting time, cropping patterns, and others by utilizing information from GCM outputs. However, the information provided by GCM is still on a global scale and has a low resolution for local scale forecasting. However, GCM output information can still be utilized by using statistical downscaling techniques. Statistical Downscaling is a technique that connects GCM output as a predictor variable with local rainfall in Jember Regency as a response variable with the intermediary of a functional model. The response variable, namely local rainfall in Jember, was taken from January 2005 to December 2018 with a total of 168 data. As for the GCM output response variables, there are three types of variables used in this study, namely precipitation, sea surface pressure, and air temperature with a $3 \times 3$ domain to a $10 \times 10$ domain. The two data will be split with data from January 2005-December 2017 as training data to build the model and data from January 2018 to December 2018 as testing data used for model validation. In this study, rainfall forecasting in Jember Regency was carried out using two combined methods, the first method was Projection Pursuit Regression followed by the Artificial Neural Network method. For the second method, using the projection results from PPR as a dimension reducer of a large predictor variable, namely PP and followed by the Support Vector Regression algorithm. At the modeling stage with PPR, the optimum domain and many functions will be determined, where the chosen domain is a $6 \times 6$ domain and the number of optimum functions is $m=5$. Furthermore, it will be modeled using two rainfall forecasting methods, namely ANN and SVR. The results of model validation using RMSE show that the PP+SVR method has a smaller RMSE value of 65.61 compared to the PPR+ANN method with an RMSE value of 67.48. This shows that the performance for the PP+SVR model is better than the PPR+ANN model.
\end{abstract}

Keywords: General Circulation Model (GCM), Statistical Downscaling (SD), Projection Pursuit (PP), Projection Pursuit Regression (PPR), Artificial Neural Network (ANN), Support Vector Regression (SVR).

\section{INTRODUCTION}

Besides being known as a maritime country because it has a wider sea area than its land, Indonesia is also known as an agricultural country because some of its residents have a livelihood as farmers. As an agricultural country, the agricultural sector has an important role in the overall national economy [1]. However, the obstacle in the agricultural sector is climate change which can affect cropping patterns, planting time, production, and yield quality and one of the indicators of climate change is rainfall [2]. Therefore, an accurate forecasting model is 
needed to assist farmers in providing information about rainfall by utilizing information about global atmospheric circulation obtained from the General Circulation Model (GCM) [3]. However, GCM has too low resolution in predicting local rainfall but GCM can still be used to obtain local scale using the downscaling technique.

One of the downscaling techniques used to form forecasting models is statistical downscaling. The statistical downscaling model uses statistical methods to describe the relationship between data on large-scale units and data on small-scale units in a certain period. The number of variables used in forecasting rainfall causes the conventional approach is not recommended in forecasting. Therefore, a forecasting model that utilizes artificial intelligence models such as Artificial Neural Network (ANN) and Support Vector Regression (SVR) is needed. ANN is a computerized intelligence system that simulates the inductive power and behavior of the human brain and can generalize, abstract, and extract statistical properties from data. Meanwhile, SVR is based on Support Vector Machine (SVM).

ANN and SVR are models that have emerged as an alternative and a good technique for solving nonlinear regression problems. However, the large dimension of GCM output information which is a predictor variable becomes an obstacle in the study because it can potentially lead to multicollinearity. Therefore, a method is needed to reduce GCM outputs such as the Projection Pursuit (PP) contained in the Projection Pursuit Regression (PPR) model. Projection Pursuit Regression (PPR) is an SDs technique that is used to overcome the problem of predictor variables from GCM outputs that have dimensions that are too large through the projection process.

Many kinds of research on rainfall forecasting using the SDs technique have been carried out, such as Anitawati (2010) who researched rainfall forecasting using SDs modeling with the Principal Component Regression (PCR) and Projection Pursuit Regression (PPR) methods and the results showed that the PPR method had more accuracy. better than the PCR method [4]. Fauziah (2019) conducted a study on monthly rainfall in Jember by modeling SDs using the Support Vector Regression (SVR) method and found that SVR is a good SDs technique for forecasting rainfall in Jember [5]. The statistical downscaling approach uses global or regional data. One of the statistical downscaling methods that can overcome non-linear GCM data is projection pursuit (PP). So, in this case, the PP method is used to reduce GCM data, which then the reduction results are used for projection pursuit regression (PPR) modeling. The PP method is an alternative method for similar uses to principal component analysis, reducing the multiple variable data dimensions. $\mathrm{PP}$ as an estimator of the SD model [6]. Another method used for SD is an artificial neural network (ANN) [7].
Based on previous research and Indonesia's complex natural conditions, it is necessary to forecast accurate rainfall on a local scale. Therefore, researchers are interested in forecasting rainfall using the PP prediction method contained in the PPR method and combining it with the SVR algorithm. In addition, researchers are also interested in forecasting using the PPR and ANN methods. The two models are then compared to find out which model has more accurate forecasting performance.

\section{MATERIAL AND METHOD}

\subsection{Study Region}

This research was conducted in Kabupaten Jember. Kabupaten Jember is one of the districts in East Java which has an astronomical location wit $113^{\circ} 16^{\prime} 28^{\prime \prime} \mathrm{E}$ to $114^{\circ} 3^{\prime} 42^{\prime \prime} \mathrm{E}$ longitude and $7^{\circ} 59^{\prime} 6^{\prime \prime} \mathrm{S}$ to $8^{\circ} 33^{\prime} 56^{\prime \prime} \mathrm{S}$ latitude. Jember Regency has an area of 3,293.34 km2 with a topographical character of fertile canyon plains in the middle and south and surrounded by mountains that extend the western and eastern borders. Kabupaten Jember was a tropical climate with a temperature range between $23^{\circ} \mathrm{C}-32^{\circ} \mathrm{C}$. The southern part of Jember is lowland, with the outermost point being Barong Island. Temperature figures range from $23^{\circ} \mathrm{C}-31^{\circ} \mathrm{C}$, with the dry season occurring from May to August and the rainy season from September to January. Simultaneously, the rainfall is quite a lot, which ranges from $1.969 \mathrm{~mm}$ to $3.394 \mathrm{~mm}[2]$.

\subsection{Data Description}

This study uses two kinds of data, GCM precipitation data and local data. GCM precipitation which is global data used as a predictor variable. Rainfall data in Jember region which is local data used as a response variable. The data used is the daily rainfall data for 2005-2018 from the rain observation station in Jember which is then processed into monthly rainfall obtained from the BMKG Station. This data can be accessed on the BMKG website for the period January 2005 - December 2018. The data obtained for the preprocessing step are divided into two parts, in-sample data, and out-sample data. In-sample data are used as learning data to build a prediction model, while out-sample data are used to validate a model whether the model used is valid. Out sample data are used rainfall data from 2005 to 2016, while for in sample data used data for 2017 and 2018.

A plot of rainfall data with fluctuations is like in Figure 1, where the highest data or the highest rainfall is in December 2014 with maximum rainfall data reaching more than 500. While for the lowest rainfall occurs in several months of July 2018, August 2011, August 2012, September 2014, August 2015, and September 2015. Twelve years of observed data have consistent fluctuation, each year there is rainfall with low intensity 
and high intensity. For rain with high intensity occurs from October to April, while the intensity of low rainfall each year has the same fluctuation from May to September.

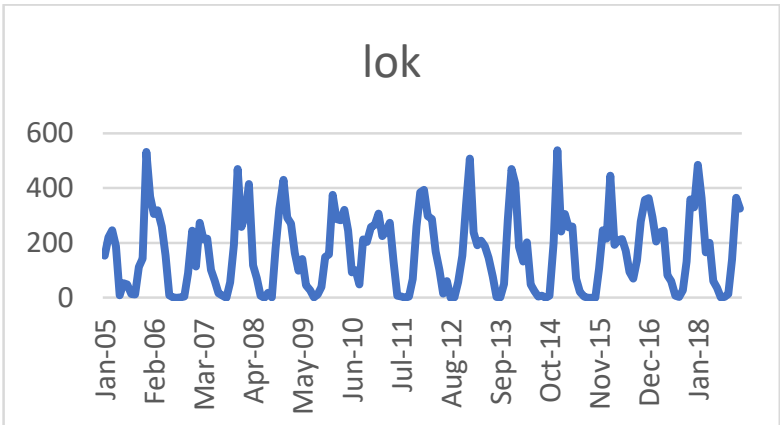

Figure 1 Monthly Rainfall Data Plot.

In Figure 2, a scatterplot of local rainfall data and GCM data is presented. After the data is displayed in a scatterplot, the first column, and the first-row show nonlinearity. Therefore, this study uses PPR as a model to reduce non-linear data dimensions. The other rows and columns are the same GCM data from a different domain.

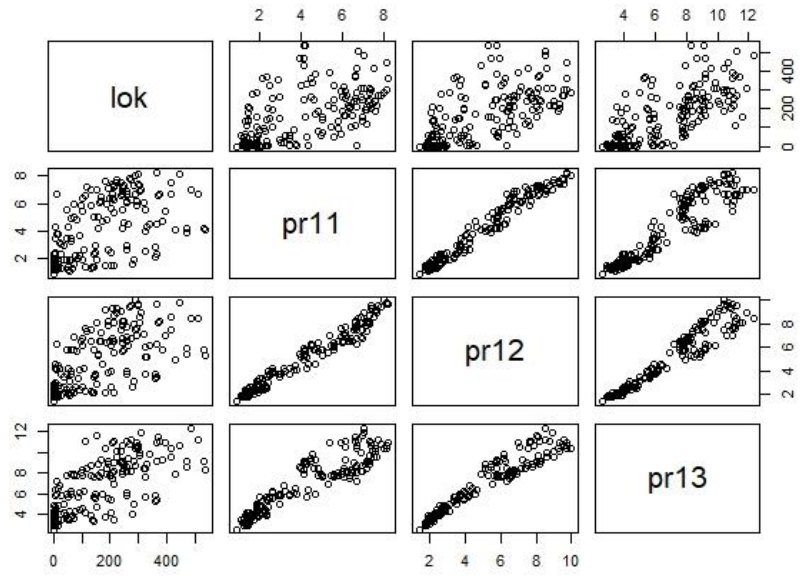

Figure 2 The plot of Response Variables and Predictor Variables.

\subsection{Method}

\subsubsection{Projection Pursuit}

Projection Pursuit (PP) is a dimensional reduction method underdispersed based on searching for a projection of primary information from largedimensional data [7]. The dimension reduction procedure using PP is carried out based on the optimum projection index, in contrast to the dimensional reduction using PCA, which is carried out based on the largest variance.

The PP method has been used for estimating the concentration of fungi, classification, and non-parametric regression, especially dealing with non-linear data structures. PP method can be used to overcome the nonlinear structure in the bear dimension data [7]. Let $X$ be a matrix data of size $t \times p$ with dimension of $g$, and $\mathrm{Z}$ is a matrix of size $t \times \boldsymbol{k}(k<p)$ as the result of the projection on $\mathrm{X}$.

If $X=\left\{x_{1}, x_{2}, \ldots, x_{p}\right\}$ is a matrix of predictor variables with dimension $\mathrm{p}$, then the linear projection $\mathfrak{R}^{p} \rightarrow \mathfrak{R}^{k}$ is written in equation 1 as follows.

$Z^{t}=A X^{t}, X \in \mathfrak{R}^{p}, Z \in \mathfrak{R}^{k}, k<p$

where $\mathrm{A}$ is the orthonormal projection coefficient matrix. The Matrix $\mathrm{A}$ is obtained by maximizing the projection index function, $\mathrm{I}(\mathrm{A})$.

Dimensional reduction with PP uses the projection index $\boldsymbol{I}\left(\boldsymbol{F}_{\boldsymbol{A}}\right)$ to obtain the maximum of matrix A through numerical optimization of the parameters(equation 2 ). $I(Z)=I\left(A X^{T}\right)=I(A)$

The projection index $I(A)$ can be obtained from the following equation 3 .

$$
I(A)=1-\frac{\sum_{i=1}^{t}\left(r_{i}-S_{\alpha}(A X)\right)^{2}}{\sum_{i=1}^{t} r_{i}^{2}} .
$$

\subsubsection{Projection Pursuit Regression}

Projection Pursuit Regression (PPR) is one of the nonparametric and nonlinear regression methods to process data in large dimensions that can describe information in small dimensions through the projection process [8]. Thus, PPR can solve the problem of local averages, polynomial functions, and recursive partitioning. PPR model begins with maximizing the index projection, determines the functions of a single variable on a basis empirical based on optimum projections, as well adds up these functions [9].

Based on [10], the PPR algorithm is as follows. The regression surface is approximated by a sum of empirically determined univariate functions Sum of linear combinations of the predictors:

$\varphi(\mathrm{X})=\sum_{m=1}^{M} S_{\alpha(m)}(Z)$

where $Z=\left(\alpha_{(m)} \cdot X\right)$ and $\alpha_{(m)}$ is a vector coefficient of A that maximize the Projection index of $\mathrm{I}(\alpha)$ as follow:

$I(\alpha)=1-\frac{\sum_{i=1}^{t}\left(y_{i-} s_{\alpha}\left(\alpha \cdot x_{i}\right)\right.}{\sum_{i=1}^{t} y_{i}^{2}}$.

The approximation is constructed in an iterative manner.

1. Determine the initial residual value and the value of $M$ (number of functions) as written in equation 4 and 5 below.

$r_{i} \leftarrow y_{i}, \quad i=1,2, \ldots, t$

$M \leftarrow 0$

where $\sum y_{i}=0$. The number of functions is determined based on function optimization $m=1,2,3,4,5$ and determining the number of functions selected based on the best validation results.

2. Determine $\boldsymbol{\alpha}$ and $S_{\alpha}$ in the model.

For linear combination, $\boldsymbol{Z}=\boldsymbol{\alpha}_{\boldsymbol{m}} \boldsymbol{X}$, determined smooth function $\boldsymbol{S} \_\boldsymbol{\alpha}(\boldsymbol{Z})$ according to the $\mathrm{Z}$ values using the projection index $\mathbf{I}(\boldsymbol{\alpha})$. As for the projection index $\mathbf{I}(\boldsymbol{\alpha})$ can be calculated using equation 6 below. 
$I(\alpha)=1-\frac{\left.\sum_{i=1}^{t}\left(r_{i}-S_{\alpha\left(\alpha x_{i}\right.}\right)\right)^{2}}{\sum_{i=1}^{t} r_{i}^{2}}$

Determine the coefficient vector $\alpha_{M+1}$ that maximizes $I(a)$ (projection pursuit), $\alpha_{M+1}=$ $\max _{\alpha}^{-1}(I(\alpha))$ and the smooth function is $S_{\alpha_{M+1}}(Z)$.

3. End of Algorithm

If $\mathbf{I}(\boldsymbol{\alpha})$ is smaller than the threshold value then it stops. But, if $\mathbf{I}(\boldsymbol{\alpha})$ is greater than the threshold value, the residual value and $M$ value are changed as written in the following equation 7 and 8 .

$r_{i} \leftarrow r_{i}-S_{\alpha}(Z), i=1,2, \ldots, t$

$M \leftarrow M+1$

And return to the previous step. The threshold value is obtained from the linear combination boundary in the scatterplot between the response variable and the predictor variable. The following (equation 9 and 10) is the end of the PPR algorithm:

$y_{i}=\sum_{m=1}^{M} S_{-} \alpha_{m}\left(a_{m} X\right)$

$=\beta_{0}+\sum_{m=1}^{M} \beta_{m} f_{m}\left(\sum_{k=1}^{n} \alpha_{k m} X_{i k}\right)+\varepsilon_{i}$

$S_{-} \alpha_{m}\left(a_{m} X\right)$ is an unknown function and $\alpha_{m}=$ $\alpha_{1 m}, \alpha_{2 m}, \ldots, \alpha_{k m}$ is a unit vector where $m$ is the basis of the function. $X_{i}=\left(X_{i 1}, X_{i 2}, \ldots, X_{i k}\right)$ is the $\mathrm{k}$-th predictor variable and the i-th observation, $y_{i}$ is a response variable, $\varepsilon_{i}$ is a random vector with $E\left(\varepsilon_{i}\right)=0$ and $\operatorname{var}\left(\varepsilon_{i}=\sigma^{2}\right)[11]$.

\subsubsection{Artificial Neural Network (ANN)}

Artificial Neural Network Artificial (ANN) is an information processing technique or approach inspired by the workings of the biological nervous system, especially in human brain cells in processing information. The key element of this technique is the structure of the information processing system which is unique and varied for each application. Neural Network consists of a large number of information processing elements (neurons) that are connected and work together to solve a particular problem, which is generally a classification or prediction problem.

Neural networks usually have unique artificial neurons and the model of a multilayer neural network. The signal flow from inputs $x_{1}, x_{2}, x_{3}, \ldots x_{n}$ is considered to be unidirectional, and $w_{1}, w_{2}, w_{3} \ldots w_{n}$ are associated weights to the corresponding inputs. The acceleration or retardation of the input signals is formed by the weights to account for the strength. Hence the total input received is written in equation 11 :

$I=w_{1 \times 1}+w_{2 \times 2}+\cdots+w_{n \times n}$

The sum is passed on to a non-linear filter called Activation Function $\Phi$ (equation 12) which forms the thresholding process. The sum will be compared with threshold value $\boldsymbol{\theta}$, if $\boldsymbol{I}>\boldsymbol{\theta}$ then output is 1, otherwise 0 (equation 13).

$\boldsymbol{y}=\boldsymbol{\phi}(\boldsymbol{I})$

$y=\sum_{i=0}^{n} w_{i} x_{i}-\theta$.

\subsubsection{Support Vector Regression}

Support Vector Regression (SVR) is an application of the Support Vector Machine (SVM) model in the case of regression. SVR is a method that functions to overcome the problem of overfitting so that it will affect the results of good performance and find a function as a hyperplane (separation line) in the form of a regression function $(x)$ which can approximate the output to an actual target by minimizing the error function $(\varepsilon)$ [12].

For example, training data $\left[\left(x_{1}, y_{1}\right),\left(x_{2}, y_{2}\right), \ldots,\left(x_{l}, y_{l}\right)\right]$ with input vector $x_{i}$ and output vector $y_{i}$ is a continuous number, so SVR wants to find the regression function which is written in equation 14 as follows:

$\mathrm{f}(\mathrm{x})=\mathrm{w}^{\mathrm{T}} \varphi(\mathrm{x})+\mathrm{b}$

where $\mathrm{w}$ is the weighting vector and $\varphi(x)$ is a function that maps $\mathrm{x}$ in a dimension and $\mathrm{b}$ is a bias.

To get the optimal hyperplane, it is done by maximizing the margin. Maximizing margin can be done by minimizing $\|w\|$ or $\|w\|^{2}$ as written in equation 15. It is, therefore, necessary to solve the following optimization problems:

$\min \frac{1}{2}\|\mathrm{w}\|^{2}$

which fulfills the requirements (equation 16 and 17):

$\mathrm{y}_{\mathrm{i}}-\mathrm{w} \varphi\left(\mathrm{x}_{\mathrm{i}}\right)-\mathrm{b} \leq \varepsilon$

$\mathrm{w} \varphi\left(\mathrm{x}_{\mathrm{i}}\right)-\mathrm{y}_{\mathrm{i}}+\mathrm{b} \leq \varepsilon, \mathrm{i}=1,2, \ldots, \lambda$

All points are assumed to be in the range $f(x) \pm \varepsilon$ (feasible). However, in the case of infeasible, where some points may be out of range $f(x) \pm \varepsilon$, so it is necessary to add a slack variable $\xi$ and $\xi^{*}$ to overcome the problem of an infeasible constraint in an optimization problem as shown in Figure 3.

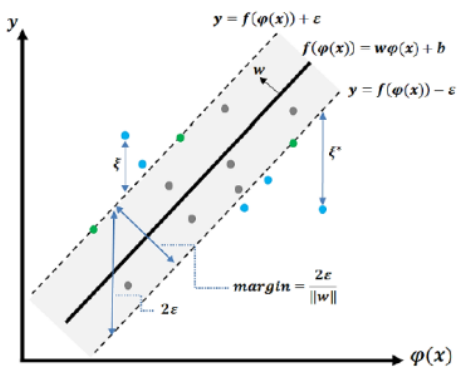

Figure 3 The hyperplane of SVR.

Furthermore, the optimization problem above can be formulated in equation 18 as follows:

$\min \frac{1}{2}\|\mathrm{w}\|^{2}+\mathrm{C} \frac{1}{1} \sum_{\mathrm{i}=1}^{\mathrm{l}}\left(\xi_{\mathrm{i}}+\xi_{\mathrm{i}}^{*}\right)$

that fulfills (equation 19, 20, 21)

$\mathrm{y}_{\mathrm{i}}-\mathrm{w}^{\mathrm{T}} \mathrm{j}\left(\mathrm{x}_{\mathrm{i}}\right)-\mathrm{b}-\xi_{\mathrm{i}} \leq \varepsilon, \mathrm{i}=1,2, \ldots, \mathrm{l}$

$w j\left(x_{i}\right)-y_{i}+b-\xi_{i}^{*} \leq \varepsilon, i=1,2, \ldots, l$

$\xi_{\mathrm{i}}, \xi_{\mathrm{i}}^{*} \geq 0$

The optimization solution can be solved by finding the dual form using Lagrange multiplication, so that the Lagrange function formed is as follows: 
$\mathcal{L}\left(\mathrm{w}, \mathrm{b}, \xi, \xi^{*}, \alpha, \alpha^{*}, \mathrm{\eta}, \mathrm{n}^{*}\right)=\frac{1}{2}\|\mathrm{w}\|^{2}+\mathrm{C} \sum_{\mathrm{i}=1}^{\mathrm{l}}\left(\xi_{i}+\right.$

$\left.\xi_{\mathrm{i}}^{*}\right) \sum_{\mathrm{i}=1}^{\mathrm{l}} \alpha_{\mathrm{i}}\left(\mathrm{y}_{\mathrm{i}}-\mathrm{w}^{\mathrm{T}} \varphi\left(\mathrm{x}_{\mathrm{i}}\right)-\mathrm{b}-\varepsilon-\xi_{\mathrm{i}}\right)+$ $\varphi\left(\mathrm{x}_{\mathrm{i}}\right) \sum_{\mathrm{i}=1}^{\mathrm{l}} \alpha_{\mathrm{i}}^{*}\left(\mathrm{~b}+\mathrm{w}^{\mathrm{T}}-\mathrm{y}_{\mathrm{i}}-\varepsilon-\xi_{\mathrm{i}}^{*}\right)-\sum_{\mathrm{i}=1}^{\mathrm{l}}\left(\mathrm{n} \xi_{\mathrm{i}}+\mathrm{n}^{*} \xi_{\mathrm{i}}^{*}\right)$

To get the optimal solution, the partial derivative of the Lagrange function is carried out with respect to $w, b, \xi, \xi^{*}$. From the above equation $\mathrm{w}$ can be written as equation 23 below:

$\mathrm{w}=\sum_{\mathrm{i}=1}^{\mathrm{l}}\left(\alpha_{\mathrm{i}}-\alpha_{\mathrm{i}}^{*}\right) \varphi\left(\mathrm{x}_{\mathrm{i}}\right)$

Then the optimal hyperplane is written:

$\mathrm{f}(\mathrm{x})=\sum_{\mathrm{i}=1}^{n S V}\left(\alpha_{\mathrm{i}}-\alpha_{\mathrm{i}}^{*}\right) \varphi^{\mathrm{T}}\left(\mathrm{x}_{\mathrm{i}}\right) \varphi\left(\mathrm{x}_{\mathrm{j}}\right)+\mathrm{b}$

As for calculating the dot product $\varphi^{T}\left(x_{i}\right) \varphi\left(x_{j}\right)$ in equation (24) is calculated using the kernel function $k\left(x_{i}, x\right)=\varphi^{T}\left(x_{i}\right) \varphi(x)$ so it is explicitly formulated in equation 25 as follows:

$\mathrm{f}(\mathrm{x})=\sum_{\mathrm{i}=1}^{n S V}\left(\alpha_{\mathrm{i}}-\alpha_{\mathrm{i}}^{*}\right) \mathrm{k}\left(\mathrm{x}_{\mathrm{i}}, \mathrm{x}\right)+\mathrm{b}$

Some common kernel functions used in SVM literacy are:

Table 1. Kernel SVM

\begin{tabular}{lc}
\hline \multicolumn{1}{c}{ Kernel } & Definition \\
\hline 1. Linear & $K\left(x_{i}, x_{j}\right)=x_{j}^{T} x_{i}$ \\
2. Polynomial & $K\left(x_{i}, x_{j}\right)=\left(x_{j}^{T} x_{i}+1\right)^{p}$ \\
$\begin{array}{l}\text { 3. RBF (Radial } \\
\text { Basis Function) }\end{array}$ & $K\left(x_{i}, x_{j}\right)=\exp \left(-\frac{\left\|x_{i}-x_{j}\right\|^{2}}{2 \sigma^{2}}\right)$ \\
4. Sigmoid & $K\left(x_{i}, x_{j}\right)=\tanh \left(\alpha x_{j}{ }^{T} x_{i}+\theta\right)$ \\
\hline
\end{tabular}

\subsubsection{Method Evaluation}

In this case, the performance of the PPR model was evaluated using Root Mean Square Error (RMSE). RMSE is a performance index to determine the accuracy of the PPR model in predicting the target values [4]. RMSE is a measure of how to spread out these residuals or error that has occurred between the test values and the predicted values. A smaller RMSE value indicates a better model, mathematically (equation 26):

$R M S E=\sqrt{\frac{1}{n} \sum_{i=1}^{n}\left(y_{i}-\hat{y}_{i}\right)^{2}}$

\section{MODEL DEVELOPMENT}

In this study, two variables were used, namely predictor variables and independent variables. The response variable in this study is local rainfall in Jember Regency with a period of January 2005 to December 2018. As for the predictor variable, the data period used follows the period of the response variable, namely January 2005 to December 2018. The two data are then divided into two, namely training data and testing data. Training data is used to build a model with data used from
January 2005 to December 2017. Meanwhile, testing data is used to validate the model with data used in the period January 2018 to December 2018. The predictor variable, namely GCM output, involves several domains for forecasting rainfall. from the smallest domain that is $3 \times 3$ to the largest domain of 10x10. Each domain has many different variables because there are three types of predictor variables used, so the $3 \times 3$ domain has a total of 27 predictor variables.

In the SDs model using PPR, the steps taken before setting the rainfall forecasting model are to determine the optimum number of functions and domains. In determining the optimum function and domain, it can be seen from the smallest RMSE value.

Based on Table 2, the optimum function is located at $\mathrm{m}=5$ and the optimum domain is located at $6 \times 6$. This is because the $\mathrm{m}=5$ and $6 \times 6$ domains have the smallest RMSE value compared to the RMSE value in other functions and domains, which is 22.79 .

Table 2. Minimum RMSE Value for Each Domain

\begin{tabular}{cr}
\hline Domain Size & \multicolumn{1}{c}{ RMSE } \\
\hline $3 \times 3$ & 23.12 \\
$4 \times 4$ & 27.41 \\
$5 \times 5$ & 23.31 \\
$6 \times 6$ & $\mathbf{2 2 . 7 9}$ \\
$7 \times 7$ & 25.46 \\
$8 \times 8$ & 30.74 \\
$9 \times 9$ & 26.11 \\
$10 \times 10$ & 24.41 \\
\hline
\end{tabular}

\section{RESULT AND DISCUSSION}

Many optimum functions, namely $\mathrm{m}=5$ and optimum domain 6x6 with 108 predictor variables will be used to build an accurate PPR model. Furthermore, the PPR model will be combined with the ANN model. It did not stop there, the research was continued by using the reduction method in the PPR model, namely PP to build other forecasting models. The PP reduction method will be combined with the SVR algorithm and produce a comparison of forecasting results using PPR+ANN, $\mathrm{PP}+\mathrm{SVR}$, and PPR with the actual data as follows. 
Table 3. Comparison of forecasting results of PPR, $\mathrm{PP}+\mathrm{SVR}, \mathrm{PPR}+\mathrm{ANN}$ with actual data

\begin{tabular}{ccccc}
\hline Month & Actual & PPR & SVR(PP) & PPR+ANN \\
\hline Jan-18 & 485.013 & 486.064 & 309.406 & 380.3422 \\
Feb-18 & 363.872 & 363.873 & 322.930 & 293.7831 \\
Mar-18 & 164.923 & 164.875 & 246.431 & 196.0471 \\
Apr-18 & 200.167 & 196.992 & 265.362 & 211.7999 \\
May-18 & 60.936 & 60.313 & 73.680 & 93.0959 \\
Jun-18 & 35.859 & 36.128 & 51.732 & 46.90766 \\
Jul-18 & 1.449 & 0.041 & 12.271 & 26.21182 \\
Aug-18 & 2.551 & 5.591 & 53.465 & 15.07176 \\
Sep-18 & 13.718 & 16.248 & 1.017 & 29.38189 \\
Oct-18 & 139.769 & 73.741 & 86.472 & 64.66991 \\
Nov-18 & 365.231 & 352.099 & 355.180 & 223.4819 \\
Dec-18 & 325.359 & 562.263 & 280.253 & 424.1979 \\
\hline Based & & & &
\end{tabular}

Based on Table 3, we get a plot of the results of the comparison of rainfall forecasting in 2018 using the PPR, PPR + ANN, PP + SVR models, and the actual data.

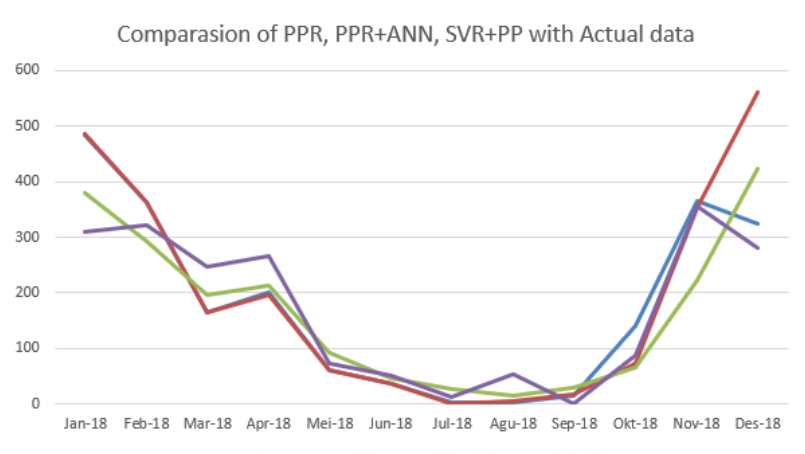

-

Figure 4 The plot of Comparison forecasting results of PPR, PP+SVR, PPR+ANN with actual data.

Furthermore, to find out which performance is better between the three forecasting models, namely PPR, $\mathrm{PPR}+\mathrm{ANN}$, and $\mathrm{PP}+\mathrm{SVR}$, it can be seen from the validation values of the three models using RMSE. Following are the results of the validation of the three models with RMSE.

Table 4. RMSE values of the three forecasting models

\begin{tabular}{cccc} 
& PPR & PPR+ANN & SVR(PP) \\
RMSEP & 71.11 & 67.48 & 65.61 \\
\hline
\end{tabular}

Based on the validation value above, it can be seen that the rainfall forecasting model that has the smallest RMSE value is the forecasting model using the PP+SVR method with an RMSE value of 65.618283 which indicates that the PP+SVR model has better performance than the other two models, namely PPR and PPR. PPR+ANN.

\section{CONCLUSION}

The three models show that the forecasting performance is not much different, indicated by the small difference in the RMSE value between the models. However, when compared between the three models, the forecasting model using the PP+SVR method has better performance because it has a smaller RMSE value than the other two models.

\section{ACKNOWLEDGMENTS}

We would like to thank the Ministry of Research and Technology/National Research and Innovation Agency of Indonesia, especially The Directorate of Research and Community Empowerment (DRPM). This paper was part of the research funded by the DRPM with contract number 175/SP2H/AMD/LT/DRPM/2020. We also thanks to all member of the Data Science Research Group at the Department of Mathematics, University of Jember.

\section{REFERENCES}

[1] S. Sukirno, Makro Ekonomi Modern (in Indonesian), PT. Rajawali Grafindo Persada, Jakarta, 2002.

[2] Nurdin, Antisipasi Perubahan Iklim untuk Keberlanjutan Ketahanan Pangan (in Indonesian), Jurnal Dialog Kebijakan Publik, vol. 4, pp. 21-31, 2011.

[3] R. Wilby, and T. Wigley, Downscaling General Circulation Model Output: A Review of Method ana Limitations, Progress in Physical Geography, vol. 4 pp. 530-548, 1997.

[4] M. Anitawati, Pemodelan Statistical Downscaling Luaran GCM dengan Metode Principal Component Regression (PCR) dan Projection Pursuit Regression (PPR) (in Indonesian), Thesis, Institut Teknologi 10 Nopember, 2010.

[5] A. Fauziah, D. Anggraeni, A. Pradjaningsih, A. Riski, A. F. Hadi, Support Vector Regression in Statistical Downscaling for Rainfall Forecasting. International, Journal of Scientific \& Technology Research, vol. 9, pp. 5665-5669, 2020.

[6] A.H. Wigena, and Aunuddin, Beberapa Model Statistical Downscaling untuk Peramalan Curah Hujan (in Indonesian), in Proc. of Pertemuan Ilmiah Nasional Basic Science 1, Brawijaya University, Indonesia, 2004.

[7] A.H. Wigena, and Aunuddin, Aplikasi Projection Pursuit dan Jaringan Syaraf Tiruan Dalam Pemodelan Statistical Downscaling (in Indonesian), Statistika Forum Teori dan Aplikasi, vol. 4, no. 2, pp. 7-10, 2004. 
[8] M.A. Agmalaro, Pemodelan Statistical Downscaling Data GCM Menggunakan Support Vector Regression untuk Memprediksi Curah Hujan Bulanan Indramayu (in Indonesian), Thesis, Institut Pertanian Bogor, 2011.

[9] A. Wigena, Pemodelan Statistical Downscaling dengan Regresi Projection Pursuit Untuk Peramalan Curah Hujan Bulanan (in Indonesian), Dissertation, Institut Pertanian Bogor, 2006.

[10] J.H. Friedman, and W. Stuetzle, Projection Pursuit Regression, Journal of the American Statistical
Association, vol. 76, pp. 817-823, 1981. https://doi.org/10.1080/01621459.1981.10477729

[11] V.R. Asyiefa, Pemodelan Statistical Downscaling dengan Projection Pursuit Regression untuk Meramalkan Curah Hujan Bulanan di Sentra Produksi Padi Jawa Timur (in Indonesian), Thesis, Institut Teknologi 10 Nopember, 2017.

[12] B. Schölkopf, and A. J. Smola, Learning with Kernels: Support Vector Machines, Regularization, Optimization, and Beyond, Massachusetts Institute of Technology Press, 2002. 